\title{
Statement by the ILO on the Occasion of the International Day of Disabled Persons, 3 December 1995
}

Having a disability should no longer be a reason for not having a job. New technologies and working methods, but also a generally better education and a higher level of skills and competencies give people with disabilities today a much better chance to join the workforce than in the past. Many employers have recognized this and offer disabled workers job opportunities at an equal level with other workers.

On the other hand, world unemployment is on the increase and the globalization of the economy seems to push ever larger number of workers into the margins of society. Disabled people figure prominently among those who are the first to be fired and the last to be hired. The struggle for jobs and survival gets tougher every day.

An estimated five percent of the workforce has some kind of disability or, to be more precise, an impairment or some functional limitation. By definition, they are employed or are looking for a job. Many other disabled persons of working age are unable to work or have ceased trying to find employment, and live on pensions, public assistance or family support. The unemployment rate among disabled workers is often double, sometimes triple that of non-disabled workers. In developing countries where social protection systems are weak or non-existant, their situation is even more precarious. Jobs in the informal sector are exploitive, hazardous and badly paid. Begging is common.

Will this situation ever improve? Are United Nations declarations that promote equal treatment and opportunity for disabled persons simply empty promises? Are disabled people the inevitable victims of a free and global market? Do policy makers just pay lip-service when they speak of human rights? Is the decline in public funding to support disability programmes permanent?

There are no easy answers. Political recognition that disabled people need to find their rightful place in the labour market has increased. Much progress has been made in recent years to reinforce protective policies and support measures. International instruments have been gaining ground. For example, ILO Convention No. 159 concerning the Vocational Rehabilitation and Employment of Disabled Persons has to date been ratified by 55 countries. The UN Standard Rules on the Equalization of Opportunities for Persons with Disabilities has stimulated great interest and positive action in many countries. Disabled people have mobilized and fight for their rights.

However, employment discrimination continues on a massive scale while many disabled people are not really prepared for the challenges of a competitive economy. These are key concerns of the International Labour Office. The ILO has been at the forefront of the battle for the welfare and social justice of workers since its inception in 1919. During the recent UN World Summit on Social Development in Copenhagen it was given the responsibility of promoting full and equitable employment. The ILO has allocated considerable financial and staff resources to fight discrimination against disabled people, to improve their labour market competencies and to promote their economic integration.

During 1995, the ILO provided policy advice and supported development activities related to 
the labour market integration of disabled persons in some 40 countries. It also developed a strategy for following up on the Programme of Action of the UN World Summit on Social Development and is active within the framework of the Asian and Pacific Decade of Disabled Persons. The ILO has prepared policy guidelines that concern issues of labour market integration as well as those that promote skill acquisition and work opportunities within the framework of community-based rehabilitation programmes.

Therefore, on this International Day of Disabled Persons, the ILO invites governments, employers' and workers' organizations, as well as organizations of and for disabled persons, to take a fresh and unbiased look at the issue of disabled persons and employment. It proposes a joint search for effective, practical and feasible approaches and measures to achieve employment equity for persons with disabilities. For many, giving a job to an individual with a disability is a social and humanitarian issue; for others a human rights issue. For employers, it is an issue of the competitiveness of their enterprises. One need not be opposed to the other.
For its part, the ILO is working to demonstrate that equity can be reconciled with efficiency and that an equitable employment policy is as relevant and useful a tool for governments and employers as ever. It has recently initiated the creation of a global network that unites universities, research centres and interested organizations in a programme of research and data collection to identify the most efficient and cost-effective solutions in assisting disabled people to participate as equals in the economic activities of their communities and countries.

Once fully operational, this network will generate analyses and information that will be useful for policy-makers, employers, unions and disability organizations alike, to help them to improve training and employment measures for people with disabilities.

For more information please contact:

International Labour Office

4 route des Morillons

CH-1211 Geneva 22

Switzerland 